\title{
DISPERSÃO NATURAL DE SEMENTES: IMPORTÂNCIA, CLASSIFICAÇÃO E SUA DINÂMICA NAS PASTAGENS TROPICAIS*
}

\author{
NATURAL DISPERSION OF SEEDS: IMPORTANCE, CLASSIFICATION AND DYNAMICS \\ IN TROPICAL PASTURES
}

Deminicis, B.B ${ }^{1}$, H.D. Vieira², S.A.C. Araújo ${ }^{3}$, J.G. Jardim4 ${ }^{4}$ F.T Pádua ${ }^{5 A}$ e

A. Chambela Neto ${ }^{5 B}$

${ }^{1}$ Universidade Estadual do Norte Fluminense Darcy Ribeiro. UENF. Av. Alberto Lamego, 2000. CEP 28013600. Campos dos Goytacazes, RJ. Brasil. brunodeminicis@hotmail.com

${ }^{2}$ LFIT/UENF. Brasil. henrique@uenf.br

3UENF. UFRRJ. Rodovia BR 465, km 7. CEP 23890-000. Brasil. araujosac@yahoo.com.br

${ }^{4}$ Universidade Estadual do Oeste do Paraná. UNIOESTE. Rua Pernambuco, 1777. Marechal Cândido

Rondon. CEP 85960-000. Paraná. Brasil. julia@zootecnista.com.br

${ }^{5} U E N F$. Brasil. Aftpadua@uenf.br; ${ }^{\mathrm{B}}$ chambela@gmail.com

\section{PalaVRas chaVe adicionais}

Plantas forrageiras. Dispersores. Ruminantes.

\section{RESUMO}

A propagação de plantas pela dispersão de sementes é reconhecida como um dos fatores fundamentais que afetam o recrutamento das plantas e é um importante passo do ciclo reprodutivo da maioria delas. A dispersão reduz os níveis de predação nas proximidades dos adultos da mesma espécie, aumenta as chances de germinação das sementes e estabelece novos habitats favoráveis a colonização. Além disso, a dispersão de sementes também gera a distribuição espacial dos indivíduos adultos da população. Embora seja reconhecida a importância da ressemeadura natural na renovação e persistência de espécies em pastagens, o entendimento do processo de dispersão sob nova perspectiva dentro dos modernos modelos de produção, que se pautam na sustentabilidade, onde temos, lado a lado, animais silvestres e produção pecuária baseada em pastagens é um assunto pouco conhecido. Com essa revisão, objetivou-se traçar

*Financiada pela Fundação Carlos Chagas Filho de Amparo à Pesquisa do Estado do Rio de Janeiro (FAPERJ), pelo Conselho Nacional de Desenvolvimento Científico e Tecnológico (CNPq) e pela Coordenação de Aperfeiçoamento de Pessoal de Nível Superior (CAPES).
ADDITIONAL KEY WORDS

Forage plants. Dispersers. Ruminants. a trajetória dos estudos sobre dispersão de sementes, com ênfase nos sistemas de classificação, os tipos, os dispersores, o processo de dispersão de sementes entre habitats, avaliação do potencial de dispersão de espécies vegetais através de ruminantes e as aplicações e limitações atuais da dispersão de sementes, e assim contribuir para a construção dessa nova concepção de desenvolvimento baseada na sustentabilidade dos sistemas de produção agropecuários.

\section{SUMMARY}

The plant propagation by seed dispersion is recognized as one of the fundamental factors that affect the recruitment of the plants and is an important step of the reproductive cycle of most of them. The dispersion reduces the predation levels in the proximities of adult plants of the same species, increases the chance of seed germination and establishes new habitats favorable to the colonization. Besides, the dispersion of seeds also generates wider spacial distribution of adult plants population. The importance of natural seeding in the renewal and persistence of species in pastures is recognized, but it is a little known subject, the understanding of the dispersion 
process under a new perspective from the point of view of modern, sustainability based, production models, where wild animals are compatible with agricultural production based on pastures. With this revision, it was aimed to trace the path of the studies on dispersion of seeds, with emphasis in the classification systems, the types, the dispersers, the seeds dispersion processes among habitats, the evaluation of the dispersion potential of vegetable species through ruminant, and the applications and current limitations of seeds dispersion, and contribute for construction of a new development conception based in sustainability of the agricultural production systems.

\section{INTRODUÇÃO}

As plantas produtoras de sementes provavelmente apareceram há cerca de 350 milhões de anos e as sementes teriam surgido como uma extensão da heterosporia em resposta a pressões ambientais (Carvalho e Nakagawa, 2000). O grande sucesso da semente como órgão de perpetuação e de disseminação das espécies vegetais devese, provavelmente a capacidade de distribuir a germinação no tempo e no espaço. A semente tem como papel biológico a conservação e a propagação da espécie, devendo germinar quando as condições são adequadas para a manutenção do crescimento da plântula e subseqüente desenvolvimento da planta.

A dispersão de sementes é um processo fundamental do ciclo de vida de cada espécie vegetal e se trata do deslocamento dos propágulos vegetais a partir da planta-mãe (para distâncias "seguras") (Cordeiro e Howe, 2003). As chances de recrutamento próximo à planta-mãe podem ser muito baixas devido à competição e predação de sementes. À medida que as sementes se afastam da planta mãe, maior é a probabilidade de sobrevivência das plântulas. Do ponto de vista técnico, a disseminação ou dispersão natural das sementes se constitui num importante meio para a regeneração natural e perpetuação de povoamentos vegetais. podendo ser considerada como o proce- dimento que antecede à colonização de plantas, assumindo grande importância no entendimento da regeneração natural de ecossistemas vegetais. Essa colonização desempenha um papel fundamental no estabelecimento, desenvolvimento e evolução das espécies vegetais, permitindo, assim, o intercâmbio de material genético dentro e fora de diferentes populações.

O processo de dispersão, independente da forma de ocorrência, é muito complexo e envolve relações muito específicas entre plantas e diferentes agentes dispersores. Já os mecanismos de dispersão das sementes poderiam ser encarados como os meios pelos quais a espécie vegetal tenta " promover essa conquista por novas áreas. O estudo da dispersão de sementes por animais prova ser uma ferramenta útil para a análise da estrutura dos ecossistemas das pastagens, merecendo ser mais e melhor aproveitada. A dispersão de sementes também é importante para a recuperação de áreas degradadas por atividades antrópicas pois, para que se obtenham sistemas auto-sustentáveis, é necessário considerar a sucessão vegetal na recuperação dessas áreas.

\section{CLASSIFICAÇÃODOSTIPOSDE DISPERSÃONATURAL}

No passado, foram desenvolvidas várias classificações dos tipos de dispersão natural de sementes (Dansereau e Lems, 1957; Müller-Schneider, 1977; Luftensteiner, 1982; Van Der Pijl, 1982; Grime et al., 1988; Jenny, 1991; Frey e Hensen, 1995). Porém, algumas destas classificações ignoram certos modos de dispersão, como a dispersão através da água (Luftensteiner, 1982) ou todos os tipos de dispersão por atividade humana (Van Der Pijl, 1982; Jenny, 1991). As classificações existentes falham claramente ao separar os modos de dispersão apenas por caracteres morfológicos das plantas dispersas.

A simples dedução de que, na maioria dos casos, um único tipo de dispersão 


\section{DISPERSÃO NATURAL DE SEMENTES EM PASTAGENS TROPICAIS}

baseada apenas em características morfológicas torna óbvio que estes estudos por décadas foram falhos (Berg, 1983). Além disso, provavelmente estes pesquisadores que criaram os sistemas de classificação dos tipos de dispersão, nunca tenham medido ou observado as espécies vegetais no campo. Embora as características morfológicas das sementes sugiram informações importantes sobre o potencial de dispersão, a classificação rígida baseada em certas características morfológicas das sementes, concebendo só um modo de dispersão, pode resultar em uma interpretação completamente errada do real potencial de dispersão das espécies vegetais. Por exemplo, muitas espécies de gramíneas que são classificadas como baixo potencial de dispersão por apresentar autocoria ou semacoria (Müller-
Schneider, 1986), podem ser dispersas em altas quantidades em longas distâncias por bovinos (Fischer et al., 1996). Mas, de acordo com esta classificação, o potencial de dispersão destas espécies é limitado em curtas distâncias.

Desta forma, este fato indica a existência de modos alternativos de dispersão. Nestes casos, a dispersão em longas distâncias não tem sido efetuada somente por atividade humana (por cultivo, etc.) ou hidrocoria (ao longo dos rios) (Hartmann et al., 1995). Estes exemplos ilustram aquelas espécies que podem ser dispersas potencialmente através de diferentes vetores ("policoria"). Porém, os tipos de dispersão atuais também dependem da estrutura do ecossistema em que estão inseridas as espécies, bem como das faixas agrícolas e diferentes tipos de

Tabla I. Classificação de tipos de dispersão baseados no vetor de dispersão. (Classification of dispersion types based on the dispersion vector).

\begin{tabular}{|c|c|c|}
\hline \multicolumn{2}{|c|}{ Tipo de dispersão } & Dispersão por... \\
\hline \multirow[t]{3}{*}{ Autocoria } & Balocoria & Expulsão pela planta-mãe (cápsulas ou bagas secas) \\
\hline & Blastocoria & Deposição ativa pela planta mãe \\
\hline & Herpocoria & Mecanismos de turgor ou movimentos hidroscóspicos. \\
\hline Barocoria & & Disseminação da semente pelo peso do fruto \\
\hline Semacoria & & $\begin{array}{l}\text { Movimentos de ramos e galhos da planta mãe causados por } \\
\text { forças externas (vento) }\end{array}$ \\
\hline Anemocoria & Anemocoria & Vento \\
\hline \multirow[t]{3}{*}{ Hidrocoria } & Ombrocoria & Expulsão causada por gotas de chuva \\
\hline & Nautocoria & Flutuação na superfície da água \\
\hline & Bythisocoria & $\begin{array}{l}\text { Correntes de água: transporte submerso, onde a correnteza atua } \\
\text { sobre estruturas como pêlos ou arilóides }\end{array}$ \\
\hline \multirow[t]{7}{*}{ Zoocoria } & Mirmecocoria & Formigas \\
\hline & Ornitocoria $^{1}$ & Pássaros ${ }^{2}$ \\
\hline & Mamaliocoria ${ }^{1}$ & Mamíferos² \\
\hline & Antropocoria & Homem $^{2}$ \\
\hline & Ictiocoria & Peixes (por ingestão) \\
\hline & Saurocoria & Répteis (por ingestão) \\
\hline & Outros $^{1}$ & Outros animais ${ }^{2}$ \\
\hline \multirow[t]{3}{*}{ Hemerocoria } & Agocoria & Ação humana (movimento do solo) \\
\hline & Speirocoria & Cultivo de lotes de sementes com sementes de plantas daninhas \\
\hline & Ethelocoria & Cultivo de sementes comerciais \\
\hline
\end{tabular}

1epizoo-, endozoo-, zoogeo-; '²na superfície do corpo, por ingestão ou via transporte para alimentação. A negrita indica alto potencial de dispersão. Adaptado de Hansson et al., (1992). 
uso do solo. Por isso, a classificação dos tipos de dispersão (tabela I) deve ser também baseada em vetores de dispersão e não apenas em características morfológicas das sementes das espécies estudadas.

\section{CLASSIFICAÇÃODE CARACTERÍSTI- CAS DE PLANTAS PARA DISPERSÃO DE SEMENTES}

Várias características da unidade de dispersão (semente) ou da planta inteira podem afetar a "dispersabilidade" por certos vetores. Para avaliar o potencial de dispersão de uma espécie, temos que observar quais características estão relacionadas aos diferentes tipos de dispersão, ou afetando o tipo de dispersão ou ainda a distância de dispersão. Durante os últimos anos, poucos estudos foram capazes de avaliar a "dispersabilidade" relacionando espécies vegetais ou características das sementes a diferentes tipos de dispersão (Hodkinson e Thompson, 1997; Thompson etal., 1999).

Por muito tempo não houve nenhuma proposta para um novo sistema de classificação que incluísse a associação de características da planta e da semente com o potencial de dispersão, levando em consideração todos os possíveis vetores de dispersão. Contudo, Bonn (2004) propôs um sistema de classificação (tabela II) que leva em consideração os tipos e o potencial de dispersão entre populações ou novos habitats (dispersão em "longa distância", Hasson et al., 1992).

Embora os tipos de dispersão se restrinjam a um potencial de dispersão de curta distância, são importantes para a estrutura, dinâmica e determinação das populações locais (Husband e Barrett, 1996), por isso Bonn (2004) em sua proposta para novo sistema de classificação, decidiu excluir todos os tipos de dispersão da classificação. Sua principal justificativa foi de manter um banco de dados tão simples quanto possível, baseado em análises da viabilidade das espécies em uma determinada paisagem, não considerando apenas as populações, mas sim um jogo de populações na paisagem; várias possibilidades de espécies dispersas dentro de um habitat e a falta de vetores adequados para dispersão, embora os potenciais de dispersão possam ser altos. As características que foram consideradas como relevantes nesta proposta de classificação estão brevemente detalhadas a seguir.

Tempo e período de dispersão afetam o potencial de todos os tipos de dispersão, determinando se as sementes são liberadas quando um vetor de dispersão específico está disponível, como por exemplo, animais pastejando durante o período das chuvas, bem como a altura e densidade de vegetação, queda de liteira e mudança de velocidade de vento durante as estações (Johnson 1988). A altura das plantas, dos frutos e sementes nas plantas: não só determina se uma semente está dentro do alcance de certo vetor (por exemplo, um animal, certas máquinas e/ou em alguns casos também da água), mas também a trajetória e a distância de dispersão no caso de anemocoria (Bonn, 2004). Alto número de sementes produzidas: as mais variáveis distâncias e as maiores áreas de dispersão podem ser garantidas por certos vetores de dispersão. Além disso, a distribuição de sementes por área pode ser aumentada. Finalmente, aumento do número de sementes aumenta a chance de pelo menos algumas germinarem e chegar a se tornarem uma planta adulta, conduzindo a dispersão absoluta nas mais altas distâncias. Desta forma, todos os tipos de dispersão são afetados por esta característica. A ocorrência de hidrofilia ou hidrofobia: significa que a cápsulas, onde as sementes estão abrigadas, abrem exclusivamente de acordo com as condições climáticas, e é especialmente importante no caso de dispersão por anemocoria, por exemplo: a baixa umidade oferece melhores condições para sementes aladas, assim uma seca favorece a dispersão em longas distâncias. Em 


\section{DISPERSÃO NATURAL DE SEMENTES EM PASTAGENS TROPICAIS}

contraste, espécies dependentes de alta umidade abrem suas cápsulas durante os dias chuvosos (Van Der Pijl, 1982).

O tamanho e forma das sementes podem afetar a sobrevivência após passagem pelo trato digestivo dos animais dispersores, isto porque sementes pequenas e esféricas apresentam maiores taxas de sobrevivência, justamente porque são menos suscetíveis aos danos de mastigação e por que

Tabla II. Características relevantes de sementes e plantas para dispersão a longa distância. (Important characteristics of seeds and plants for long distance dispersion).

\begin{tabular}{rrr}
\hline Características & Anemo- $\begin{array}{c}\text { Zoo- } \\
\text { Hidro- }\end{array}$ & Hemero- \\
& $\mathrm{Ep} \mathrm{Ed} \mathrm{Zg} \mathrm{Na} \mathrm{By} \mathrm{Sp}$ \\
\hline
\end{tabular}

I. Características das plantas e dos frutos

Tempo e duração da propagação de sementes começo e fim em meses durante meses

Produção de sementes número

Sementes dispersas por ciclo número

Altura dos frutos e sementes a serem dispersos (na planta) metros

Xenofobia (hidrofilia) ou Hidrofobia sim ou não

$\begin{array}{lllllll}\text { A } & \text { A } & \text { A } & \text { A } & \text { A } & \text { A } & \text { A } \\ \text { A } & \text { A } & \text { A } & \text { A } & \text { A } & \text { A } & \text { A } \\ \text { A } & \text { A } & \text { A } & \text { A } & \text { A } & \text { A } & \text { A } \\ \text { A } & \text { A } & \text { A } & \text { A } & \text { A } & \text { A } & \text { A } \\ \text { A } & \text { A } & \text { A } & \text { A } & \text { B } & \text { B } & \text { A } \\ \text { A } & - & - & - & \text { B } & - & -\end{array}$

II. Características morfológicas das sementes

Classificação segundo tamanho e forma comprimento $(\mathrm{mm})$ largura $(\mathrm{mm})$ altura $(\mathrm{mm})$ forma ( $n^{\circ}$ calculado)

Morfologia das sementes categorização (carrapicho, pluma, tegumento duro...) $\quad$ C $\quad$ C C - C - B

Peso das sementes/ gravidade específica $[\mathrm{mg}] /[\mathrm{g} / \mathrm{ml}$

$\begin{array}{lllllll}\text { C } & \text { C } & \text { C } & - & \text { C } & \text { B } & \text { A } \\ \text { C } & \text { C } & \text { C } & - & \text { C } & \text { B } & \text { A } \\ \text { C } & \text { C } & \text { C } & - & \text { C } & \text { B } & \text { A } \\ \text { C } & \text { C } & \text { C } & - & \text { C } & \text { B } & \text { A } \\ \text { C } & \text { C } & \text { C } & - & \text { C } & - & \text { B } \\ \text { C } & \text { C } & \text { C } & \text { B } & \text { C } & \text { B } & \text { A }\end{array}$

III. Parâmetros indicativos

Velocidade final $[\mathrm{m} / \mathrm{s}$ ]

Capacidade de aderência (em diferentes tipos de pelagem) $\% /$ unidade de tempo

Tolerância a passagem pelo trato digestivo (taxa de sobrevivência) \%

Flutuabilidade dias

"Ep: Epi-; Ed: Endo-; Zg: Zoogeo-; Na: Nauto-; By: Bythis-; Sp: Speiroc-. A: característica de alta importância para certo tipo de dispersão; B: possuem importância secundária ou importância apenas para algumas espécies; C: podem resumir os parâmetros adequados. Adaptado de Bonn (2004). 
freqüentemente passam mais rapidamente pelo trato digestivo dos animais (Gardener et al., 1993a). Além disso, sementes pequenas podem ser dispersas através de epizoocoria, ou seja, aderidas externamente à estes animais, como por exemplo nos casacos de javalis e lã de ovelhas (Schneider etal., 1994; Mrotzeketal., 1999). Espécies com sementes pequenas apresentam dispersão distribuída ao longo do tempo, enquanto sementes grandes têm dispersão concentrada em determinados períodos (Marimon e Felfili, 2006). O Peso das sementes e gravidade específica tem importância em diferentes tipos de dispersão, pois podem, por exemplo, afetar a capacidade das sementes serem dispersas por endozoocoria, porque podem influenciar no tempo de retenção no trato digestivo dos animais (Gardener et al., 1993a). Obviamente, o tamanho e forma das sementes também afetam a epizoocoria, a nautocoria (Van Der Pijl, 1982), a anemocoria (Greene e Johnson, 1993) e na dispersão através da colheita com sementes de plantas daninhas (McDonald e Smith, 1990).

A morfologia das sementes (superfície com ganchos, "asas" e tegumento duro): afeta todos os tipos de dispersão de zoocoria (Mrotzek etal., 1999). No caso de epizoocoria a existência de ganchos, ou cerdas, que "grudam" na pele ou pêlos, faz com que as sementes sejam transportadas com eficiência (Stender et al., 1997). No caso de sementes com tegumento duro e liso aumentam a chance de sobrevivência ao trato digestivo dos animais. Embora o vento possa funcionar como vetor de dispersão, a existência de tipos de "asas" nas sementes favorece a dispersão em longas distâncias. Além disso, a morfologia pode afetar a flutuação das sementes na água (Özer, 1979).

Para vários tipos de dispersão é possível medir o valor agregado das várias características morfológicas das sementes. Estes parâmetros permitem uma avaliação mais precisa e mais fácil do potencial de dispersão por certo vetor (Andersen, 1991). Adicio- nalmente, estes parâmetros podem facilitar a classificação dos processos de dispersão, desde que possam ser considerados como parâmetros de contribuição direta para os mecanismos de dispersão.

Porém, informações sobre a maioria destes parâmetros são escassas. Neste sentido, uma padronização dos métodos empregados para obter estes parâmetros é um aspecto importante a ser considerado em pesquisas futuras (Bonn, 2004). A velocidade final de dispersão é um desses parâmetros indicativos que já foi utilizado como padrão para uma grande quantidade de espécies (Tackenberg, 1999; Thompson et al., 1999). A associação com as alturass das plantas e altura das sementes na planta (flores e frutos) pode ser usado como uma alternativa para avaliar o potencial de dispersão de sementes de diversas espécies, principalmente as dispersas por anemocoria (Tackenberg, 1999).

Um parâmetro relativamente preciso para se avaliar o potencial de dispersão de sementes por epizoocoria é a observação da capacidade de aderência de sementes na lã ou pele de animais. Esta determinação cão se dáatravés da porcentagem de sementes afixadas por unidade de tempo, obtidas através da aplicação de sementes sobre um animal, em uma única vez, e sua devida movimentação simulada (Fischer et al., 1996). Outro método usado é realizado através da avaliação do potencial de sobrevivência das sementes à passagem pelo trato digestivo dos animais, sendo a taxa de sobrevivência medida in vitro (Godínez-Alvareze Valiente-Banuet, 1998).

Finalmente, a "flutuabilidade" de uma semente se caracteriza no potencial de dispersão em água corrente e/ou água parada. Este parâmetro pode ser medido como a proporção de sementes que ainda flutuam depois de períodos definidos de tempo (Bill et al., 1999). Problemas podem surgir quando são usadas características das plantas para calcular o potencial de dispersão por hemerocoria, embora este modo de dispersão 


\section{DISPERSÃO NATURAL DE SEMENTES EM PASTAGENS TROPICAIS}

afete fortemente composição e riqueza de espécies em diferentes habitats (Bonn e Poschlod, 1998a,b; Poschlod e Bonn, 1998). Por outro lado, a ethelocoria parece não ser afetada por qualquer característica das plantas ou das sementes. Embora Hodkinson e Thompson (1997) citem que, neste caso, a dispersão esteja associada a certas características das plantas e das sementes, mas não depende diretamente das mesmas.

Outras características afetam o potencial de dispersão, mas são muito difíceis de serem mensuradas para a maioria das espécies. Por exemplo, o potencial de dispersão por anemocoria e epizoocoria é afetado pela "resistência de uma semente em se separar da planta mãe" (Greene e Johnson, 1992). No caso da anemocoria, por exemplo, a alta "resistência de uma semente em se separar da planta mãe" limita a dispersão das sementes à condições de vento suficientemente fortes. Devido à "resistência de separação variável" de uma semente, as forças necessárias para separar uma semente da planta-mãe podem variar consideravelmente (Augspurger e Franson, 1987).

Portanto, pode-se afirmar que a dispersão de sementes tem estreita relação entre plantas e dispersores, o que pode tornar crítico a manutenção do sistema, uma vez que a remoção de um ou outro pode afetar de modo irreversível o equilíbrio das populações, sendo sua importância principal atribuída ao aumento da sobrevivência de plântulas (Saravy et al., 2003). Nas regiões tropicais, a dispersão de sementes por hemerocoria (práticas agrícolas) e por zoocoria são as principais formas de dispersão de sementes, por isso são importantes contribuições para a recolonização e reestruturação de sua vegetação natural.

\section{DISPERSÃO DE SEMENTES ATRAVÉS DEPRÁTICASAGRÍCOLAS}

No passado, a agricultura também incluía o uso de áreas de florestas, que duran- te milênios foi o mais importante uso do solo e, desta forma, teve grande influência na formação de diversas paisagens em todo mundo. Por causa desta influência, seu papel deve ser considerado no contexto atual das práticas agrícolas, já que estas podem introduzir espécies não desejadas a um sistema agrícola, por meio da dispersão de sementes (Bonn, 2004). Porém, com o uso de algumas destas práticas agrícolas pode-se introduzir, de forma proposital, algumas espécies de interesse agrícola ou zootécnico, como por exemplo, Cavariani et al. (1994) e Rezende et al. (2007) que misturaram sementes de gramíneas com fertilizantes para o plantio das mesmas.

\section{DISPERSÃO DE PLANTAS DANINHAS POR LOTES DE SEMENTES CONTAMINADOS}

A infestação de lavouras e pastagens por muitas ervas daninhas sempre foi muito comum e normalmente esta espécies são introduzidas através de lotes de sementes contaminados. Embora métodos simples para limpeza de sementes já existam há muito tempo (Knörzer, 1971), a limpeza de sementes permaneceu bastante ineficaz até o fim do século XIX. Durante milênios, a colheita de semente conteve altas quantias de sementes de ervas daninhas (Schneider et al., 1994). Um método bastante simples de limpeza de sementes tem sido amplamente utilizado pelas empresas de sementes, é a separação das impurezas (palha, gravetos, torrões de solo, sementes de plantas daninhas, etc.) por máquinas ou manualmente, baseada em diferenças no tamanho, peso e morfologia das sementes (Tackenberg, 2001). $\mathrm{Na}$ verdade, quando falamos limpeza, estamos nos referindo ao Beneficiamento de sementes, que é um conjunto de operações que se estendem desde a colheita até o armazenamento e que visam retirar as impurezas das sementes, deixando-as puras para a semeadura e/ou comercialização (Schumacher etal, 2002).

Para Silva et al. (1993), beneficiamento consiste num conjunto de técnicas 
empregadas para retirar impurezas e sementes de outras espécies, promovendo a homogeneização do lote em relação às características de tamanho, peso e forma de suas sementes. Segundo Nogueira (2002), o beneficiamento de sementes é feito baseando-se em diferenças de características físicas entre a semente e o material indesejável, ou seja, o beneficiamento consiste na retirada de sementes chochas, imaturas, quebradas, sementes de outras espécies, pedaços de frutos, resíduos da colheita, insetos, dentre outras impurezas. Assim, o lote de sementes vai apresentar maior pureza física e, conseqüentemente, melhor qualidade. (Hoppe e Witschoreck, 2004).

Entretanto, de acordo com estudos realizados por Kauter (2002), até mesmo após realizado beneficiamento de um lote de sementes, ocasionalmente, são encontradas sementes de plantas daninhas. Isto acontece especialmente em regiões de produção de grãos, mas que, com o cultivo, acabam propagando plantas daninhas e estas acabam se perpetuando na região e quase que se tornando uma espécie cultivada (Konold e Hackel, 1990).

DISPERSÃO DE SEMENTES ATRAVÉS DE DIFERENTES FERTILIZANTES

As limitações químicas devido à acidez do solo e a deficiência crônica de nutrientes, bem como o continuo uso do solo são características históricas marcantes na agricultura tradicional, conduzindo ao uso de uma grande variedade de corretivos e fertilizantes. (Kauter, 2002). Tradicionalmente, a adubação orgânica acompanhou o homem na sua agricultura, predominando até as primeiras décadas do século XX, e o uso deste tipo de fertilizante garantiu a dispersão de espécies entre diferentes habitats. Justamente por que a adubação orgânica tipicamente consiste no uso de uma grande variedade de resíduos orgânicos como: palhas, cascas, carcaças de animais mortos, liteira de floresta (folhas mortas e material senescente), etc., como também de excrementos de bovinos, aves e suínos, entre outros animais (figura 1). Sendo que o esterco animal contém milhares de sementes de espécies vegetais.

A adubação orgânica é uma pratica agrícola muito utilizada para a melhoria das propriedades químicas e físicas do solo, atuando no fornecimento de nutrientes às culturas, na retenção de cátions (Severino et al., 2006), e na complexação de elementos tóxicos, a exemplo do alumínio trocável(Lima et al., 2007) e de micronutrientes, estruturação do solo, infiltração e retenção de água, aeração e redução da compactação do solo (Costa et al., 2006). Porém, os ganhos promovidos por esses fertilizantes, podem ser reduzidos já que pode promover várias perdas, pois cada um destes fertilizantes contém certa quantidade de sementes de plantas invasoras/daninhas e que serão levadas ao campo (Bonn, 2004). Atualmente, a transferência direta de fertilizantes de outros habitats, como de florestas, é quase que inexistente, exceto em alguns países da Europa onde os produtores rurais tradicionalmente aproveitam resíduos de suas florestas. Na maior parte do mundo, a fertilização dos solos é realizada com o uso de fertilizantes minerais ou esterco animal, que na sua maioria é isenta de sementes de qualquer espécie ou contém normalmente poucas sementes.

A causa mais óbvia para o baixo conteúdo de sementes no esterco é que as forrageiras, utilizadas na alimentação de bovinos, bubalinos, ovinos e caprinos são utilizadas sob curtos períodos de corte ou rebrota (intervalo entre pastejos), o que não permite na maioria das vezes a produção de sementes por essas forrageiras ou por invasoras. Entretanto, se observa frequentemente no Brasil manejos inadequados em termos de freqüência de corte/pastejo, que permitem a emissão de inflorescências pelas forrageiras. Apesar disto, a longevidade das sementes no esterco é freqüentemente mais baixa que em fezes frescas, devido ao período de 
armazenamento (curtimento), temperatura de armazenamento e a toxidez por amônia, a qual promove forte seleção de espécies (Kellerer e Albrecht, 1996). Todavia, as sementes com tegumento duro são menos sensíveis a amônia, o que significa que a dispersão de sementes nas pastagens pela distribuição de esterco curtido será limitada (Rieder, 1966).

\section{DISPERSÃO ATRAVÉS DE MÉTODOS DE COLHEITA}

A dispersão de plantas daninhas em pastagens e campos de produção de cereais é determinada em grande parte pelos métodos de colheita. Na antiguidade, a colheita era realizada manualmente ou por cortes com facas, sendo que a altura de corte/ colheita era semelhante a de espécies daninhas, fazendo com que essas espécies tivessem suas sementes colhidas junto com as da cultura cultivada, desta forma foi responsável por contribuir para a dispersão destas espécies. A colheita de espécies de porte baixo ou decumbentes também favorece a colheita de espécies de plantas daninhas (Willerding, 1986). Apesar destes fatos, os métodos de colheita não mudaram

No passado

Atualmente

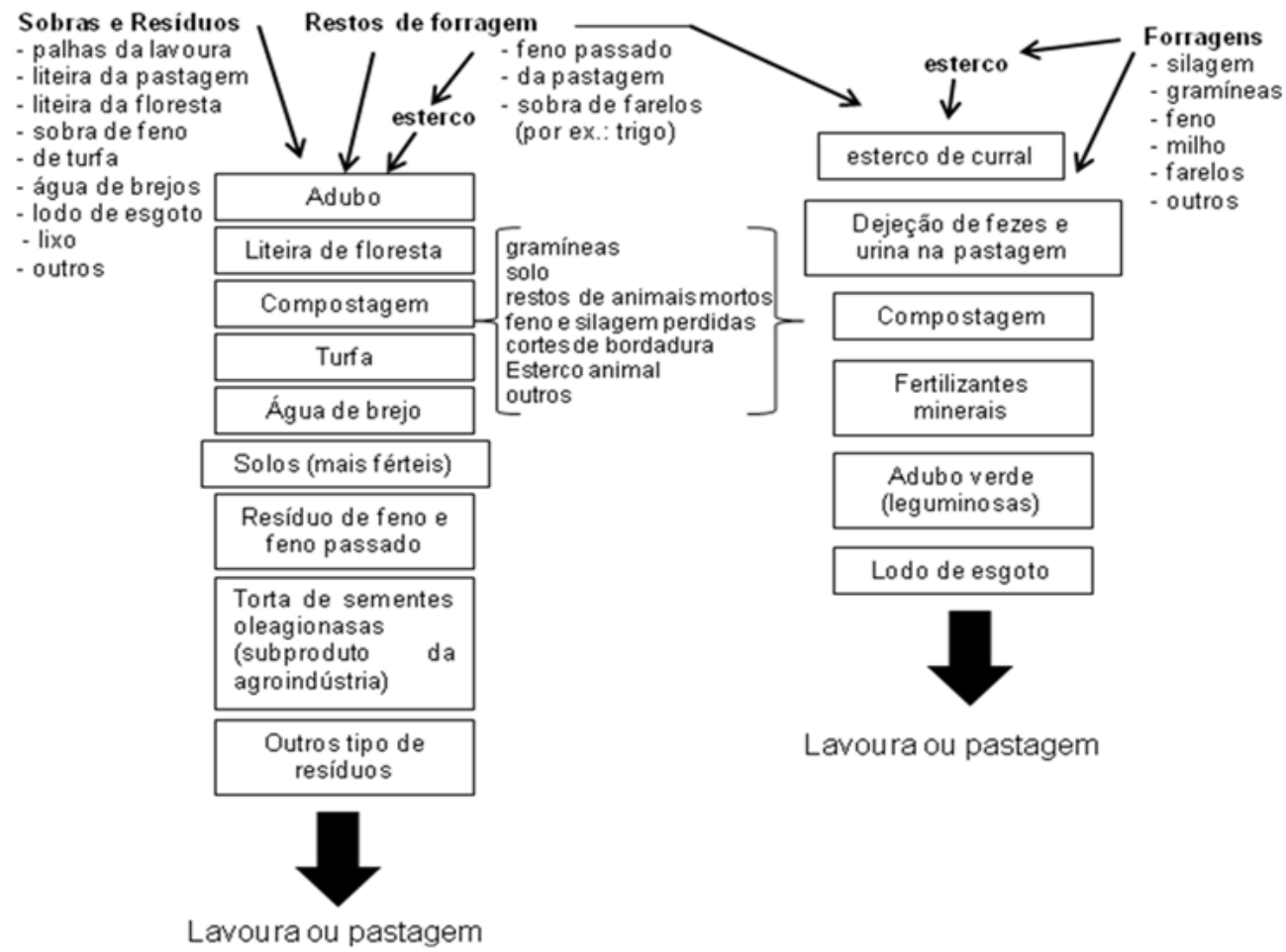

Figura 1. Fertilizantes utilizados nas lavouras e nas pastagens no passado e no presente. Adaptado de Bonn (2004). (Fertilizers used in the farms and pastures in the past and present. Adapted from Bonn (2004)). 
muito ao longo do tempo. Por exemplo, na colheita manual ou mecânica do milho, realizada quando da maturação dos grãos, há a separação da palha e da semente, mas na palha permanece parte das sementes das plantas daninhas, e essa palha volta ao campo, contribuindo para a dispersão das plantas daninhas. Essa palha também pode ser recolhida e fornecidacomo forragem à bovinos, caprinos ou ovinos, oque promove a infestação das fezes com essas sementes, e conseqüentemente, volta à lavoura ou pastagem. Outro exemplo de dispersão através da colheita por máquinas pode ser comprovada por Strykstra et al.(1996), onde os autoresconstataram que o maquinário utilizado para fenação é um importante vetor de dispersão de plantas daninhas em campos de produção de feno. Resumindo, diferentes métodos de colheita influenciam os padrões de dispersão de espécies de plantas daninhas nas lavouras e nas pastagens e podem ter grande impacto econômico, pois as espécies invasoras competem por luz, água e nutrientes com a cultura cultivada (Ghersa et al., 1993).

\section{DISPERSÃO DE SEMENTES POR ANIMAIS (ZOOCORIA)}

Há na literatura especializada grande número de trabalhos demonstrando o papel de animais como agentes dispersores de sementes (Pizo e Simão, 2001; Cazzeta et al., 2002; Galetti e Francisco, 2002; Castro e Galetti, 2004; Krügel et al., 2006), através do consumo das mesmas, sendo que parte delas é destruída e outra parte sobrevive e germina (Gardener, 1993; Malo e Suárez, 1995; Stender et al., 1997; Pakeman et al., 2002; Bonn, 2004; Deminicis, 2005). Estima-se que, em regiões tropicais, até $90 \%$ das espécies possuem suas sementes dispersas por animais (Liebsch, 2007). Nesta interação, as plantas necessitam de agentes dispersores eficientes que garantam a sobrevivência e o desenvolvimento de suas sementes. Como contrapartida, os animais utilizam os nutrien- tes dos tecidos vegetais em suaalimentação. Todavia, diversos estudos têm demonstrado que as diferentes espécies de animais não apresentam a mesma eficiência como dispersoras (Galetti e Francisco, 2002). Vários fatores podem influenciar na eficiência deste processo, tais como, o número de sementes dispersas por defecção, a qualidade do tratamento dado à semente (via tubo gastrointestinal), qualidade do tegumento das sementes, bem como a qualidade da deposição destas sementes. Segundo Mikich e Silva (2001), o período mais propício para a dispersão das sementes e para o estabelecimento das plântulas é durante a estação chuvosa) provavelmente em função de condições climáticas e da maior atividade dos animais dispersores neste período do ano.

\section{DISPERSÃO DE SEMENTES POR FORMIGAS (MIRMECORIA)}

A mirmecocoria é a dispersão de sementes por formigas. Esse fenômeno não é considerado especializado, já que há o envolvimento de uma grande diversidade de formigas associadas às sementes. Passos e Ferreira (1996), estudando a dispersão de sementes de Croton priscus Croizat (Euphorbiaceae), identificaram 11 espécies de formigas que interagem com as sementes. Horvitz e Schemske (1986) observaram cinco espécies de formigas em contato com sementes de Calathea ovandensis Matuda (Marantaceae). Muitos gêneros de Formicidae são relatados como dispersores de sementes, como é o caso de Formica, Myrmica e Aphaenogaster, comuns nas florestas temperadas da Europa e América do Norte, além de espécies de Rhytidopone, Pheidole e Iridomyrmex, provenientes da Austrália (Handel e Beattie, 1990). Nas regiões de Cerrado do Brasil foram identificados, por Leal e Oliveira (1998), vários gêneros de Attini, dispersores de sementes, como Cyphomyrmex, Mycetarotes, Mycocepurus, Myrmicocrypta, Sericomyrmex e Trachymyrmex, incluindo ainda as cortadeiras 


\section{DISPERSÃO NATURAL DE SEMENTES EM PASTAGENS TROPICAIS}

Atta e Acromyrmex. Contudo, o papel das formigas cortadeiras como dispersoras de sementes de plantas não-mirmecocóricas permanece pouco conhecido (Silva, P.D. et al., 2007). As espécies de formigas que interagem com sementes diferem na morfologia e na biologia, assim como as espécies de plantas mirmecocóricas diferem no tamanho das suas sementes (Santo, 2007). Sementes pequenas tendem a ser removidas por formigas pequenas e sementes grandes, por formigas grandes, que possuem fortes mandíbulas (Peternelli et al., 2004).

\section{DISPERSÃO DE SEMENTES POR AVES (OrNITOCORIA)}

Grande parte dos estudos sobre dispersão de sementes por animais envolve a utilização de aves, devido a sua abundância e freqüência com que se alimentam de sementes (Francisco e Galetti, 2002). Entretanto, a maior parte destes estudos têm se baseado apenas na observação da utilização de uma única espécie de planta por várias espécies de aves (Francisco e Galeti, 2002; Krügel et al., 2006).

Diferentes espécies de plantas apresentam características que podem influenciar na atração das aves frutívoras, como a quantidade de frutos produzidos, o valor nutritivo dos frutos, a presença de compostos secundários e a variedade de cores (Francisco et al., 2007). Geralmente, o grupo de aves consumidoras de uma determinada espécie de fruto é constituída por uma ampla variedade taxonômica, exibindo grande diversidade trófica e morfológica (Galetti e Pizo, 1996). Por outro lado, diversos estudos têm demonstrado que as espécies de aves que consomem sementes não apresentam a mesma eficiência como dispersores. Apesar disto, como agentes dispersores de sementes, as aves têm um imprescindível papel na regeneração de florestas, além de introdução de espécies em pastagens, principalmente em áreas onde há reservas de mata, pois carregam as sementes das matas para áreas impactadas ou degradadas, promovendo a sua reconstituição. Assim, a dispersão natural de sementes tem sido avaliada como um fator de importância na recomposição e para a conservação de ecossistemas (Bancroft et al., 1995). Desta forma, alguns trabalhos (Pizo et al., 2002; Cazetta e Galleti, 2007) têm investigado a dieta frugívora de algumas espécies de aves, com o objetivo de fornecer subsídios para o desenvolvimento deplanos de manejo agroflorestal sustentáveis. Estes estudos se baseiam na compreensão da dispersão de sementes, tendo como premissa o respeito à capacidade de resiliência da natureza.

\section{DISPERSÃO DE SEMENTES POR PEIXES (ICTIOCORIA)}

A maioria das espécies arbóreas de florestas de várzea frutifica no período da cheia, possibilitando que frutos e sementes sejam dispersos tanto pela água quanto por peixes. Esses frutos e sementes são fontes energéticas importantes para a alimentação de peixes (Waldhoffet al., 1996), incluindo espécies de valor comercial, como o tambaqui (Colossoma macropomum), sardinhas (Cyphocarax gilbert), pacus (Piaractus mesopotamicus) e mandis (Pimelodus spp.), que se reúnem sob as árvores que estão frutificando (Goulding, 1980; Araújo-Lima e Goulding, 1998; Claro-Jr et al., 2004). Gomiero e Braga (2003), observando os itens alimentares do lambari (Astyanax altiparanae), sugeriram que o mesmo é um dispersor de sementes de sangra-d'água (Croton urucurana), mas que a intensidade e a efetividade dessa dispersão devem, ainda, ser investigadas. Piedade et al. (2003) estudando a dispersão de sementes de palmeira (Astrocaryum jauari), nos igapós do Rio Negro na Amazônia brasileira, observou que 16 espécies de peixes exploram os frutos desta palmeira, sendo 10 possíveis dispersoras. Pela ausência de estruturas para flutuação, quando na água, as sementes da palmeira Astrocaryum afundam e, em condições hipóxicas, ocorre morte das sementes. Desta forma, a ictiocoria foi 
apontada por este autores como mecanismo essencial para colonização de novos habitats por essas plantas.

\section{DISPERSÃO DE SEMENTES POR RÉPTEIS (SAUROCORIA)}

Os répteis foram, juntamente com os peixes, os primeiros vertebrados a interagirem com plantas que possuem sementes (Tiffney, 1984). Os frutos são parte da dieta de muitas aves, mamíferos e répteis tais como tartarugas e lagartos (Iverson, 1985; Jordano, 2000). As tartarugas e os lagartos consomem grande variedade de espécies de frutos, além de folhas, flores, botões florais e sementes (Nogales et al., 1998; Lord e Marshall, 2001; Cooper e Vitt, 2002; Cooper et al., 2002).

Os lagartos são, talvez, os mais conhecidos répteis frugívoros (Castro e Galetti, 2004) Evidências estão sendo lentamente observadas de que eles podem ser importantes mutualistas em muitas regiões tropicais e temperadas (Olesen e Valido, 2003).

Entre os lagartos, muitas espécies se alimentam de frutos, destacando-se as famílias Gekkonidae, Scincidae, Iguanidae, Lacertidae, Varanidae e Teiidae (Cooper e Vitt, 2002). Na família Teiidae, existem relatos do consumo de frutos por Ameiva, Cnemidophorus, Kentropyx (Vitt et al., 2001; Cooper et al., 2002) e principalmente Tupinambis (Mercolli e Yanosky, 1994). Castro e Galetti (2004), estudando a frugivoria e edispersão de sementes pelo lagarto teiú Tupinambis merianae, verificaram que os mesmos possuem uma dieta gneralista, podendo agir como importantes dispersores de sementes em florestas semidecíduas do sudeste do Brasil Assim, segundo estes mesmos autores, estes animais podem ser dispersores de sementes de diversas espécies vegetais, devido ao grande número de sementes e frutos encontrados em seu no sistema digestivo.

\section{DISPERSÃO DE SEMENTES POR MAMÍFEROS (MAMALIOCORIA)}

Os mamíferos constituem um dos gru- pos de vertebrados que apresentam variações em seu regime alimentar (Pough et al., 1993). A partir do estudo da dieta desses animais, outras informações podem ser obtidas, como a interação planta-animal. A evolução das interações permitiu que o mutualismo entre plantas e animais atingisse seu clímax nas regiões tropicais.

Nascimento et al. (2004) observou que a cutia (Dasyprocta azarae) é o principal dispersor de sementes de acuri (Attalea phalerata Mart. ex Spreng) no Pantanal, pois consomem e não destroem as sementes dos frutos que se alimentam, espalhando sementes em até $50 \mathrm{~m}$ de distância, e muitas vezes as enterram sem danos (Dubost, 1988). Pequenos roedores são freqüentemente conhecidos por seu papel como predadores de sementes, ocasionalmente agindo também como dispersores efetivos de plantas tropicais, por carregarem sementes de um local para outro para estocagem, além disso, as sementes ingeridas que passam por seu trato digestivo não perdem seu poder germinativo, como pode ser comprovado por Azambuja et al. (2007).

Alonso-Paz et al. (1995), em áreas de planícies abertas no Uruguai, encontraram grande quantidade de sementes de Butia (Butia capitata) dispersadas através das fezes de cachorro-do-mato (Cerdocyon thous). Rocha et al. (2004) estudando, em Londrina-PR, o cachorro-do-mato como dispersor de sementes, constataram que o mesmo dispersa nove diferentes espécies de plantas, com relevante importância para a germinação de algumas sementes que passaram pelo trato digestivo do animal, o que o caracteriza como importante dispersor de sementes. Alémdisso, como este animal sobrevive em áreas degradadas, age como grande agente de recuperação destas áreas.

Entre os mamíferos, os morcegos se destacam por serem os dispersores mais importantes, podendo carregar sementes por $10 \mathrm{~km}$ (Phyllostomidae) ou até $50 \mathrm{~km}$ (Pteropodidae) (Fleming e Sosa, 1994).

Segundo Gardner (1977), os morcegos

Archivos de zootecnia vol. 58(R), p. 46. 


\section{DISPERSÃO NATURAL DE SEMENTES EM PASTAGENS TROPICAIS}

podem dispersar sementes de pelo menos 96 gêneros e 49 famílias de plantas nas regiões tropicais. Eles podem dispersar centenas de sementes por noite (Fleming e Sosa, 1994) e milhares em um período de frutificação. Diversos estudos demonstram a importância de morcegos frugívoros na regeneração de ecossistemas florestais (Charles-Dominique, 1991; Whittaker e Jones, 1994; Medellín e Gaona, 1999). Desta forma, estes animais são imprescindíveis e necessários na conservação das florestas tropicais (Sato et al., 2008). Bizerril et al. (2005) analisando fezes de antas (Tapirus terrestris), coletadas em 6 áreas de cerrado no Brasil Central e no zoológico de Brasília, constataram que este animal é potencial dispersor de sementes, pois é importante consumidor de frutos do cerrado e as sementes excretadas em suas fezes têm alta porcentagem de germinação. Primatas representam uma porção significativa dos frutívoros vertebrados nas comunidades tropicais (Garber e Lambert, 1998).

Segundo McConkey (2000), os primatas possuem importância como agentes dispersores, pois ingerem grande número de sementes dos frutos que consomem que permanecem viáveis após serem eliminadas nas fezes (Chapman, 1989). Todavia, de acordo com Figueiredo (1993) e Lapenta (2002), em geral os primatas não apresentam um efeito consistente na germinação de sementes, pois beneficiam apenas algumas espécies, enquanto prejudicam a porcentagem e/ou o tempo da germinação de outras. Lapenta (2002) estudou o papel do micoleão-dourado (Leontopithecus rosalia) como dispersor de sementes, na reserva ecológica União/IBAMA, Rio das Ostras$\mathrm{RJ}$, e verificou que este animal é responsável pela dispersão de 57 espécies de árvores e de pelo menos 17 famílias.

Dispersão por ruminantes domésticos em pastagens

Depois da extinção de numerosos "grandes mamíferos", há cerca de 10 mil anos
(Guimarães Jr. e Galetti, 2001), os ruminantes domésticos têm sido apontados como os principais vetores de dispersão de um grande número de espécies de plantas. Principalmente porque, durante séculos, as pastagens foram cultivadas com grande número de variedades de espécies vegetais, com os ruminantes normalmente se alimentando dessas plantas, como é demonstrado através de numerosos estudos (Bonn e Poschlod, 1998a).

Depois da extinção de numerosos "grandes mamíferos", há cerca de 10 mil anos (Guimarães Jr. e Galetti, 2001), os ruminantes domésticos têm sido apontados como os principais vetores de dispersão de um grande número de espécies de plantas. Principalmente porque, durante séculos, as pastagens foram cultivadas com grande número de variedades de espécies vegetais, com os ruminantes normalmente se alimentando dessas plantas, como é demonstrado através de numerosos estudos (Bonn e Poschlod, 1998a, Levine e Murrell, 2003; Andrade et al., 2005).

Particularmente com relação aos ruminantes domésticos (bovinos, bubalinos, caprinos e ovinos) existem trabalhos que observaram a germinação de sementes nas fezes destas espécies (Santos, 1999; Rodrigues, 2002) e outros que trataram de estudar a dispersão de sementes, propriamente dita (Bray et al., 1998; Michael et al., 2006). Contudo, no Brasil, os trabalhos não tratam o assunto como dispersão, abordam apenas a germinação de sementes recuperadas em fezes bovinas e ovinas (Machado et al., 1997; Rosito et al., 2000). Outros trabalhos tratam a dispersão de sementes por bovinos como um problema, pois admitem apenas a dispersão acidental de plantas daninhas ou eventual intoxicação de bovinos por sementes (Tokarnia, et al. 2000; Afonso e Pott, 2001). Em contraste com a necessidade óbvia de migrações de plantas e dispersores específicos (Cain et al., 1998, 2000; Clark et al., 1998; Pakeman, 2001), a relevância da dispersão de sementes por ruminantes do- 
mésticos em pastagens é raramenteenfatizada para a manutenção da biodiversidade de plantas e qualidade das pastagens (Fischer et al., 1996; Bonn e Poschlod, 1998a,b; Poschlod e Bonn, 1998).

Todavia, a dispersão de sementes por ruminantes pode afetar a estrutura ecológica das pastagens (Janssen, 1992). Em conseqüência deste fato, pode ocorrer diferenciação crescente das espécies nas pastagens e, em longo prazo, a extinção local de algumas espécies, com perdas crescentes, por causa da competição que algumas espécies invasoras impõem. Por um lado, a falta de adubação de pastagens pode ser compensada pela deposição natural do esterco dos bovinos na pastagem (Abel, 1978). Apesar dos danos sofridos pelas sementes na passagem através do trato digestivo dos ruminantes e na decomposição das fezes, as mesmas podem germinar e colonizar determinadas áreas com algumas espécies vegetais. No trato digestivo ocorre um processo anaeróbico, realizado por bactérias proteolíticas e celulolíticas, além de um processo enzimático ligado ao abomaso e intestino grosso, no qual as sementes são banhadas em ácido (pH 2-5) e enzimas proteolíticas, amilolíticas e lipolíticas (Teixeira, 1997). Na placa fecal, a germinação das sementes é afetada pelo processo de decomposição da matéria orgânica, efetuada pela ação de fatores abióticos, isto é, temperatura, umidade, precipitação e luz (Carvalho et al., 2000), pela ação de certos organismos, como fungos e bactérias, e de um certo número de insetos (Blume, 1984; Catts e Goff, 1992). Na estação chuvosa, as sementes germinam sob alta umidade. $\mathrm{Na}$ estação seca, ou ambientes secos, a germinação na placa fecal será fortemente afetada, justamente pelo prolongado período de desidratação da placa (Gardener et al.,1993a, b). Apesar dessas informações certamente serem úteis, elas não são conclusivas, pois a sobrevivência de sementes de várias espécies, após passagem pelo trato digestivo, é pouco conhecida.
Até agora, apenas algumas sementes de espécies tropicais foram submetidas ao trato digestivo de bovinos, tendo sido observado que entre 2 e $53 \%$ das mesmas permaneceram viáveis (Simão Neto et al., 1987; Deminicis, 2005, Silva, T.O. et al., 2007). Por isso, a sobrevivência das sementes após passagem pelo trato digestivo dos ruminantes é fator de grande relevância para a dinâmica populacional de espécies forrageiras numa pastagem. Um grande número de sementes sobrevive a essa passagem e, posteriormente, é dispersa em diferentes áreas. Assim, esses animais podem ser utilizados para introduzir uma ou mais espécies desejáveis em pastagens, disseminando sementes por um método natural, mas também podem ser responsáveis pela disseminação de espécies não desejáveis em novas áreas (Gardener, 1993).

Diante deste fato, fica óbvio a grande importância do potencial de dispersão de espécies de vegetais por endozoocoria, principalmente por bovinos. Portanto, são de extrema relevância, no contexto da conservação e recuperação de pastagens, os estudos que têm o intuito de entender as variações das comunidades vegetais e prever a biodiversidade vegetal em uma pastagem. Porém, até hoje, a quantificação do potencial de dispersão de espécies vegetais não é possível, pois há baixo número de estudos e pesquisas.

Avaliação do potencial de dispersão de espécies vegetais através de ruminantes

A dispersão de sementes após passagem pelo sistema digestivo de ruminantes é um mecanismo natural importante em pastagens. A avaliação do potencial de dispersão de plantas é então crucial no contexto de conservação e recuperação de pastagens. Porém, métodos para avaliar este potencial são restritos (Bonn, 2004), de maneira que. poucas espécies foram testadas.

Contudo, foram testadas várias metodologias para achar uma alternativa mais fácil e rápida para avaliar o potencial de dispersão 


\section{DISPERSÃO NATURAL DE SEMENTES EM PASTAGENS TROPICAIS}

de sementes. A maioria dos estudos é baseada em experiências de bovinos e ovinos com sementes introduzidas em sua alimentação. A mastigação, digestão microbiana e química são considerados os três passos básicos do sistema digestivo dos ruminantes que devem ser simulados in vitro. De acordo com Bonn (2004) a mastigação simulada (tensão mecânica por uma barra de ferro) e a digestão ácida (imersão em $0,1 \mathrm{M}$ de $\mathrm{HCl}$ por 8 horas) apresentam alta correlação com os resultados obtidos através de ensaios in vivo em ovinos e bovinos. Para leguminosas e outras espécies com dormência física, a determinação da proporção de sementes duras é proposta como um método alternativo para avaliar potencial de dispersão.

Embora, alguns estudos tenham observado correlações entre algumas características das sementes e a taxa de sobrevivência das mesmas após passagem pelo trato digestivo de ruminantes (Simão Neto et al., 1987; Russi et al,. 1992), como a massa das sementes (Thomson et al. 1990), e a gravidade especifica (Gardener et al., 1993a), o grau de confiança nestas correlações ainda é insuficiente para prever o potencial de dispersão de sementes de diversas espécies vegetais por endozoocoria, justamente por conta da diversidade observada entre a maioria das sementes das espécies estudadas.

Uma alternativa experimental para avaliação do potencial de dispersão de sementes por endozoocoria tem sido utilizada com certo grau de sucesso, e é baseada em métodos de digestão simulada in vivo, in situ e in vitro (Ocumpaugh e Swakon, 1993; Stern et al., 1997; Godínez-Alvarez e Valiente-Banuet, 1998; Remešová, 2000, Deminicis, 2005, Deminicis et al, 2008). Porém, a maioria destes estudos foi apenas com gramíneas e leguminosas, ou incluiu apenas um passo da digestão com líquido ruminal de animais fistulados, o que é indesejável como um método padrão para outros estudos, pois apresentaram correlações não satisfatórias com taxas de sobrevivência das sementes, após passagem pelo trato digestivo destes animais (Bonn, 2004).

Apesar dos déficits de aproximações existentes que tentam simular a digestão, uma aproximação experimental parece ser o modo mais exato para quantificar potencial de dispersão de sementes por endozoocoria. Porém, é clara a relevância de ensaio em degraus, considerando uma aquisição contínua de dados, de sobrevivência das sementes ao sistema digestivo dos ruminantes. Embora a sobrevivência após digestão in vitro apresente a melhor correlação com a germinação nas fezes, esta metodologia não deve ser usada exclusivamente para essa avaliação, pois pode superestimar ou subestimar a resposta de algumas espécies.Uma semente pode morrer durante a digestão em ruminantes pela destru içãopela ação da mastigação dos dentes, pelos processos microbianos e químicos, ou ainda, por simples inibição dos sucos digestivos. Desta forma, ocorre baixa correspondência entre taxas de sobrevivência de sementes submetidas à digestão in vivo e às submetidas àdigestão in vitro. Por exemplo, o efeito da mastigação durante a apreensão dos alimentos e/ou durante a ruminação pode ser perdida em métodos de simulação existentes in vitro. Além disso, a quebra mecânica de partículas é uma condição prévia importante para uma digestão adequada dos alimentos pela microbiota ruminal. Por outro lado, ensaios de digestão ruminal associados à tensão mecânica das sementes podem ser úteis para melhorar as correlações entre em taxas de sobrevivência das sementes, após passagem pelo trato digestivo dos ruminantes (Mcallister e Cheng, 1996).

\section{PROCESSO DE DISPERSÃO DE SEMENTESENTREHABITATS}

Várias hipóteses a respeito do processo de dispersão de sementes entre habitats foram resumidas por Zobel (1998) e a maioria destas hipóteses assume que todas as 
espécies têm a mesma mobilidade ou, até mesmo, que todas as espécies podem alcançar todos os habitats, e que a riqueza de espécies vegetais em diferentes ecossistemas é considerada função de fatores abióticos como água, nutrientes e luz, bem como de fatores bióticos, como os microrganismos do solo (Van Der Pij1, 1982; Ozinga et al., 1997). Embora seja óbvio e improvável que isto possa ocorrer, a maioria dos pesquisadores mantém a crença nessa possibilidade.

As paisagens naturais são caracterizadas por grande variedade de espécies animais e vegetais, que, em sua maioria, estão conectadas através de processos de dispersão de sementes (Pott, 1988). Por exemplo, áreas cultivadas com lavouras e posteriormente utilizadas como pastagens, são normalmente, dependendo de fertilidade do solo, reabitadas por espécies nativas da região (Selter, 1995). Bonn e Poschlod (1998a) observaram que, após a colheita de trigo durante anos e, posteriormente utilizada como pastagem, foi constatada a presença de diversas espécies da floresta antecessora ou de reservas próximas. A irrigação também é responsável pela conexão entre habitats, pois utiliza fontes de água que podem conter sementes de espécies de outros habitats. Lagoas artificiais ou açudes são estabelecidos em fazendas para suprir a demanda de irrigação e, assim, além da água, o esterco de curral e de esterqueiras que são utilizados na fertirrigação pode contribuir na dispersão/ introdução de espécies nestas áreas (Kleinschmidt e Rosenthal, 1995).

Levando em conta que os ruminantes domésticos sempre foram criados em florestas ou em sua sucessão, podem ser considerados, provavelmente, como os vetores mais importantes na dispersão de espécies entre habitats (Burrichter et al., 1993). A atividade pecuária de ruminantes é praticada até os dias atuais que, com suas variações, são definidas de forma mais moderna como: Pastejo de forrageiras em bosques e sub-bosques; Pastejo em sistemas agrosilvipastoris, com objetivo de produção de madeira e/ou produção animal (leite ou carne); Pastejo temporário em áreas de lavoura após colheita/ queima e/ou terrenos que encharcam durante certa época do ano; Pastejo em áreas de rotação de culturas; Pastejo em áreas com plantio de inverno, usadas no verão com lavoura.

Desta forma, os ruminantes domésticos conectam não só as áreas de lavouras e pastagem, mas também brejos, turfeiras (regiões com solos impermeáveis e mais de $70 \%$ de matéria orgânica) e florestas. Contudo, a maioria destas conexões está reduzida ou mesmo limitada, justamente pela profissionalização da pecuária com a utilização de forrageiras melhoradas, pastoreio com lotação rotativa, irrigação das pastagens e uso de pesada adubação química (Burrichter et al. 1993).

\section{APLICAÇÕESELIMITAÇÕES ATUAIS DA DISPERSÃO DE SEMENTES}

Até pouco tempo atrás, a dispersão de sementes não era discutida como fator limitante à viabilidade de populações vegetais (Fenner, 1992). Porém, com a fragmentação crescente de habitats naturais, a dispersão tem sido identificada como um fator de importância fundamental na sobrevivência de várias espécies, tanto vegetais quanto animais, pois garante a manutenção do manutenção do ambiente natural (Opdam, 1990). Desde que o conceito de metapopulação (grupo de populações da mesma espécie, separadas espacialmente e que podem interagir de algum modo) começou a ser utilizado para interpretar a dinâmica e analisar a viabilidade de populações de plantas, tem sido discutida a importância da dispersão neste processo (Silvertown e Lovett-Doust, 1993).

Desde que o conceito de metapopulação (grupo de populações da mesma espécie, separadas espacialmente e que podem interagir de algum modo) começou a ser 


\section{DISPERSÃO NATURAL DE SEMENTES EM PASTAGENS TROPICAIS}

utilizado para interpretar a dinâmica e analisar a viabilidade de populações de plantas, tem sido discutida a importância da dispersão neste processo (Silvertown e Lovett-Doust, 1993).

Considerando que a discussão era ultraconservadora, a dispersão era considerada apenas em caráter ecológico. Nos dias atuais ficou mais claroque nas paisagens artificiais (lavouras, pastagens e florestas plantadas), os vetores de sementes, combinados com práticas racionais de uso do solo, são a chave da sustentabilidade dos sistemas produtivos e do respeito ao meio ambiente (Bonn e Poschlod, 1998a,b; Poschlod e Bonn, 1998). Assim, a revisão das diferentes práticas de uso do solo mostra que há uma forte tendência para a percepção ambiental, na tentativa de compreender o processo dinâmico evolutivo, que deve cada vez mais, associa os componentes de manejo, as espécies vegetais nativas de cada região, o processo de dispersão e vetores, em cada sistema de produção. Por isso, além da polinização, a dispersão é um importante fator na manutenção do fluxo gênico das populações e indivíduos e, então, não é só uma chave importante para a sobrevivência em longo prazo de populações vegetais, dos sistemas de produção agrícola, pecuário e florestal, mas também para o planeta. Desta forma, o seu uso deve ser considerável em todos os sistemas de produção agropecuários e florestais, para conservação ambiental (Kwaketal., 1998, Oostermeijer et al., 1996). Mesmo que os processos de dispersão não possam ser restabelecidos totalmente, está claro que qualquer esforço em promover seu uso local ou regional tem grande relevância na manutenção das espécies animais e vegetais (Poschlod et al., 1998;

\section{BIBLIOGRAFIA}

Abel, W. 1978. Geschichte der deutschen Landwirtschaft vom frühen Mittelalter bis zum, 19. Jahrhundert. $3^{a}$ ed. Ulmer. Stuttgart. 333 p. Afonso, E. e A. Pott. 2001. Plantas no Pantanal
Tränkle e Poschlod, 1995; Biewer e Poschlod, 1996).

\section{CONSIDERAÇÕESFINAIS}

A dispersão de sementes por animais é uma atividade ecológica fundamental e comum nas regiões tropicais do mundo todo. Este mecanismo ajuda a manter pastagens, bosques e florestas vivas e ricas em ambientes que, muitas vezes, sofreram degradação por uso indevido do solo e/ou manejo inadequado. A compreensão da dispersão de sementes, aliada ao conhecimento das características das plantas que se pode dispersar em determinadas áreas éuma ferramenta extremamente útil para a conservação/ manutenção de áreas em equilíbrio, além da recuperação de áreas degradadas. Desta forma, assumindo que os ruminantes domésticos (bovinos, bubalinos, caprinos e ovinos) são, atualmente, os vetores de dispersão mais importantes para espécies de plantas herbáceas em pastagens, especialmente com respeito a longas distâncias, e levando em conta que esses animais são extremamente difundidos em todo o Brasil, sendo criados, além das pastagens "solteiras", em sistemas agroflorestais, em sistemas de integração lavoura-pecuária e pastagens consorciadas, têm papel de grande importância nestes sistemas de produção.

Vários estudos sobre a dispersão de sementes vêm sendo desenvolvidos nos trópicos, especialmente estudos com aves, morcegos e estudos de frugivoria, entretanto pouco se conhece sobre a dispersão de sementes por bovinos, bubalinos, caprinos e ovinos e as interações animais-plantas nas pastagens e nos sistemas agroflorestais brasileiros. tóxicas para bovinos. $1^{\mathrm{a}} \mathrm{ed}$. Embrapa, Informação Tecnológica. Brasília. Embrapa Gado de Corte. Campo Grande. 51 p.

Alonso-Paz, E., R. Rodriguez-Mazzini y M. Clara. 


\section{DEMINICIS, VIEIRA, ARAÚJO, JARDIM, PADUA E CHAMBELANETO}

1995. Dispersión de la "palma butiá" (Butia capitata) por el "zorro de monte" (Cerdocyon thous) en montes nativos de la Reserva de Biosfera Bañados del Este, Uruguay. Comunicaciones Botánicas del Museo de Historia Natural de Montevideo, 104: 1-4.

Andersen, M. 1991. Mechanistic models for the seed shadows of wind-dispersed plants. Amer. Naturalist, 137: 476-497.

Andrade, L.A., F.X. Oliveira e F.C. Ramalno. 2005. Avaliação dos impactos causados pela algaroba (Prosopisjulifora Sw.D.C.), sobre a fitodiversidade ea estrutura da caatinga. (Relatório de Pesquisa do Projeto, financiado pela Fundação o Boticário de Proteção a Natureza). 80 p.

Araújo-Lima e C.M. Goulding. 1998. Os frutos do tambaqui: ecologia, conservação e cultivo na Amazônia. Sociedade Civil Mamirauá/CNPq. Brasília. $186 \mathrm{p}$.

Augspurger, C.K. and S.E. Franson. 1987. Wind dispersal of artificial fruits varying in mass area, and morphology. Ecology, 68: 27-42.

Azambuja, B.O., D.O. Lima, V.L. Camilotti e N.C. Cáceres. 2007. Dispersão de sementes por pequenos roedores na encosta da serra geral, Rio Grande do Sul. In: Congresso de Ecologia do Brasil, 8. Anais... Sociedade de Ecologia do Brasil. Caxambu-MG.

Bancroft, G.T., A.M. Strong and M. Carrington. 1995. Deforestation and its effects on forestnesting birds in the Florida Keys. Conserv. Biol., 9: 835-844

Berg, R.Y. 1983. Plant distribution as seen from plant dispersal: General principles and basic modes of plant dispersal. Sonderband naturwissenschaftlicher Verein Hamburg. 7: 13-36.

Biewer, H. und P. Poschlod. 1996. Wiedervernässung und Wiederherstellung artenreicher Feuchtwiesen im Naturschutzgebiet "Südliches Federseeriet" (vegetationskundlicher Teil). Keimung und Etablierung von Arten nach Ansaat und Mähgutausbringung. Veröffentlichungen PAÖ, 16: 205-216.

Bill, H.C., P. Poschlod, M. Reich and H. Plachter. 1999. Experiments and observations on seed dispersal by running water in an alpine floodplain. Bull. Geobot. Inst. ETH, 65: 13-28.

Bizerril, M.X.A., F.H.G. Rodrigues and A. Hass. 2005. Fruit consumption of Dimorphandra mollis
Benth. (leguminosae) by the lowland tapir in the cerrado of central Brazil. Braz. J. Biol., 65: 407413.

Blume, R.R. 1984. Parasites of Diptera associated whith bovine droppings on a pasture in east central Texas. Southw. Entomol., 11: 215-22.

Bonn, S. 2004. Dispersal of plants in the Central European landscape. Dispersal processes and assessment of dispersal potential exemplified for endozoochory. Dissertation (Doktorgrades der Naturwissenschaften). Universität Regensburg. Stuttgart. Germany. 156 p.

Bonn, S. und P. Poschlod. 1998a. Ausbreitungsbiologie der Pflanzen Mitteleuropas. Grundlagen und kulturhistorische Aspekte. Quelle und Meyer. Wiesbaden. 404 p.

Bonn, S. und P. Poschlod. 1998b. Bedeutung dynamischer Prozesse für die Ausbreitung von Pflanzenarten seit dem Postglazial. Schrift. f. Landschaftsp. Natursch., 56: 147-171.

Bray, S.G., L. Cahill, C.J. Paton, L. Bahnisch and R. Silcock. 1998. Can cattle spread giant rats tail grass seed (Sporobolus pyramidalis) in their feces? Proceedings... Australian Agronomy Conference, 9. Wagga Wagga. Australia.

Burrichter, E., J. Hüppe und R. Pott. 1993. Agrarwirtschaftlich bedingte Vegetationsbereicherung und -verarmung in historischer Sicht. Phytocoenologia, 23: 427-447.

Cain, M.L., H. Damman and A. Muir. 1998. Seed dispersal and the holocene migration of woodland herbs. Ecol. Monogr., 68: 325-347.

Cain, M.L., B.G. Milligan and A.E. Strand. 2000. Long-distance seed dispersal in plant populations. Amer. J. Bot., 87: 1217-1227.

Carvalho, N.M. e J. Nakagawa. 2000. Sementes: ciência, tecnologia e produção. $4^{a}$ ed. FUNEP. Jaboticabal. $588 p$

Carvalho, L.M.L., P.J. Thyssen, A.X. Linhares and F.A.B. Palhares. 2000. A checklist of arthropods associated with pig carrion and human corpses in Southeastern Brazil. Mem. Inst. Oswaldo Cruz, 95: 135-38.

Castro, E.R.C. e M. Galetti. 2004. Frugivoria e dispersão de sementes pelo lagarto teiú Tupinambis merianae (Reptilia: Teiidae). Pap. Avuls Zool., 44: 91-97.

Catts, E.P. and M.L. Goff. 1992. Forensic entomology in criminal investigations. Annu. Rev. Entomol., 37: 253-72.

Archivos de zootecnia vol. 58(R), p. 52. 


\section{DISPERSÃO NATURAL DE SEMENTES EM PASTAGENS TROPICAIS}

Cavariani, C., J. Nakagawa e E.D. Velinil. 1994. Mistura de fertilizantes fosfatados com sementes de Brachiaria decumbens Stapf e Brachiaria brizantha (Hochst. ex. A. Rich) Stapf. Rev. Bras. Sem., 16: 163-167.

Cazzeta, E., P. Rubim, V.O. Lunardi, M.R. Francisco e M. Galetti. 2002. Frugivoria e dispersão de sementes de Talauma ovalata (Magnoliaceae) no sudeste brasileiro. Ararajuba, 10: 199-206.

Cazetta, C. e M. Galetti. 2007. Frugivoria e especificidade por hospedeiros na erva-depassarinho Phoradendron rubrum (L.) Griseb. (Viscaceae). Rev. Bras. Bot., 30: 345-351.

Chapman, C. 1989. Primate seed dispersal: The fate of dispersed seeds. Biotropica, 21: 148154.

Charles-Dominique, P. 1991. Feeding strategy and activity budget of the frugivorous bat Carollia perspicillata (Chiroptera: Phyllostomidae) in French Guiana. J. Trop. Ecol., 7: 243-256.

Clark, J.S., C. Fastie, G. Hurtt, S.T. Jackson, C. Johnson, G.A. King, M. Lewis, J. Lynch, S. Pacala, C. Prentice, E.W. Schupp, T. Webb and P. Wyckoff. 1998. Reid's Paradox of rapid plant migration. Dispersal theory and interpretation of paleoecological records. Bioscience, 48: 1324.

Claro-JR, L., F. Ferreira, J. Zuanon e C. AraújoLima. 2004. O efeito da floresta alagada na alimentação de três espécies de peixes onívoros em lagos de várzea da Amazônia Central, Brasil. Acta Amazon., 34: 133-137.

Cooper, W.E., J.P. Caldwell, L.J. Vitt, V. PerezMellado and T.A. Baird. 2002. Food-chemical discrimination and correlated evolution between plant diet and plant-chemical discrimination in lacertiform lizards. Can. J. Zool., 80: 655-663.

Cooper, W.E. and L.J. Vitt. 2002. Distribution, extent, and evolution of plant consumption by lizards. J. Zool., 257: 487-517.

Cordeiro, N. and H. F. Howe. 2003. Forest fragmentation severs mutualism between seed dispersers and an endemic African tree. Proc. Nat. Acad. Sci. (USA), 100: 14052-14054.

Costa, F.X., N.E.M. Beltrão, L.S. Severino, V.L.A. Lima, M.M.B. Guimarães e A.M.A. Lucena. 2006 Resposta do efeito da compactação do solo adubado com torta de mamona nos macronutrientes das folhas da mamoneira. In: Congresso Brasileiro de Plantas Oleaginosas,
Óleos, Gorduras e Biodiesel, 2. Brasília. Anais... BIPTI. Brasília-DF.

Dansereau, P. and K. Lems. 1957. The grading of dispersal types in plant communities and their ecological significance. Contributions de l'Institut Botanique de l'Université de Montréal, 71: 1-52.

Deminicis, B.B. 2005. Germinação de sementes de leguminosas forrageiras tropicais sob tratamentos químicos, físicos e biológicos. Dissertação (Mestrado em Zootecnia). Universidade Federal Rural. Rio de Janeiro. UFRRJ. Seropédica, RJ. 47 p.

Deminicis, B.B., H.D. Vieira, J.F. Coelho da Silva, S.A.C. Araújo, H.M. Vásquez, F.N. Lista e M.C. Blume. 2008. Sobrevivência de sementes de leguminosas forrageiras tropicais submetidas à degradabilidade in situ. In: Congresso Internacional de Zootecnia, 10., Anais... Universidade Federal. Paraíba. João Pessoa-PB.

Dubost, G. 1988. Ecology and social life of the red acouchy, Myoprocta exilis. Comparisons with the orange-rumped agouti, Dasyprocta leporina. J. Zool., 214: 107-123.

Fenner, M. 1992. Seeds. The ecology of regeneration in plant communities. $C A B$ International. Wallingford. $373 \mathrm{p}$.

Figueiredo R.A. 1993. Ingestion of Ficus enormis by howler monkeys (Alouatta fusca) in Brazil: efects on seed germination. J. Trop. Ecol., 9: 541-543

Fischer, S.F., P. Poschlod and B. Beinlich. 1996. Experimental studies on the dispersal of plants and animals on sheep in calcareous grasslands. J. Appl. Ecol., 33: 1206-1222.

Fleming, T.H. and V. Sosa. 1994. Effects of nectarivorous and frugivorous mammals on reproductive success of plants. J. Mammal., 75: 845-851.

Francisco, M.R. e M. Galetti. 2002. Aves como potenciais dispersoras de sementes de Ocotea pulchella Mart. (Lauraceae) numa área de vegetação de cerrado do sudeste brasileiro. Rev. Bras. Bot., 25: 11-17.

Francisco, MR., V.O. Lunardi and M. Galetti. 2007. Bird attributes, plant characteristics, and seed dispersal of Pera glabrata (Schott, 1858), (Euphorbiaceae) in a disturbed cerrado area. Bras. J. Biol., 67: 627-634.

Frey, W. und I. Hensen. 1995. Lebensstrategien bei Pflanzen: ein Klassifizierungsvorschlag. Bot. 
Jahrb., 117: 187-209.

Galetti, M. e M.R. Francisco. 2002. Aves como potenciais dispersoras de Ocotea pulchella Mart. (Lauraceae) numa área de vegetação de cerrado do sudeste brasileiro. Rev. Bras. Bot., 25: 11-17.

Galetti, M. and M.A. Pizo. 1996. Fruit eating by birds in a forest fragment in southeastern Brazil. Ararajuba, 4: 71-79.

Garber, P.A. and J.E. Lambert. 1998. Introduction to primate dispersal. Primate as seeds dispersers: Ecological processes and directions for future research. Amer. J. Primatol., 45: 38.

Gardener, C.J. 1993. The colonization of a tropical grassland by Stylosanthes from seed transported in cattle faeces. Austr. J. Agric. Res., 44: 299-315.

Gardener, C.J., J.G. Mcivor and A. Jansen. 1993a. Passage of legume and grass seeds through the digestive tract of cattle and their survival in faeces. J. Appl. Ecol., 30: 63-74.

Gardener, C.J., J.G. Mcivor and A. Jansen. 1993b. Survival of seeds of tropical grassland species subjected to bovine digestion. J. Appl. Ecol., 30: 75-85

Gardner, A.L. 1977. Feeding habits. Special publications of Museum. Texas Tech University 13: 293-350.

Ghersa, C.M., M.A. Matinez-Ghersa, E.H. Satorre, M.L. Van Esso and G. Chichotky. 1993. Seed dispersal, distribution and recruitment of seedlings of Sorghum halepense (L.) Pers Weed Res., 33: 79-88.

Godínez-Alvarez, H. and A. Valiente-Banuet. 1998. Germination and early seedling growth of Tehucan Valley cacti species: the role of soils and seed ingestion by dispersers on seedling growth. J. Arid Environm., 39: 21-31.

Gomiero, L.M. and F.M.S. Braga. 2003. O lambari Astyanax altiparanae (Characidae) pode ser um dispersor de sementes? Acta Sci. Biol. Sci., 25: 353-360.

Greene, D.F. and E.A. Johnson. 1992. Fruit abscission in Acer saccharinum L. with reference to seed dispersal. Can. J. Bot., 70 2277-2283.

Greene, D.F. and E.A. Johnson. 1993. Seed mass and dispersal capacity in wind-dispersed diaspores. Oikos, 67: 69-74.
Grime, J.P., J.G. Hodgson and R. Hunt. 1988. Comparative plant ecology: A functional approach to common British species. Unwin Hyman. London. 742 p.

Guimarães Jr., P. and M. Galetti. 2001. Frutos dispersos por mamíferos extintos. Ciência Hoje, 29: 83-85

Handel, S.N. and A.J. Beattie. 1990. Seed dispersal by ants. Sci. Amer., 263: 76-83.

Hansson, L., L. Söderström and C. Solbreck. 1992. The ecology of dispersal in relation to conservation. In: Hansson, L. (Ed.) Ecological principles of nature conservation. Elsevier Applied Science. London. p. 162-200.

Hartmann, E., H. Schuldes, R. Kübler und W. Konold. 1995. Neophyten. Biologie, Verbreitung und Kontrolle ausgewählter Arten. Ecomed. Landsberg. 302 p.

Hodkinson, D.J. and K. Thompson. 1997. Plant dispersal: The role of man. J. Appl. Ecol., 34: 1484-1496.

Hoppe, J.M. e R. Witschoreck. 2004. Sementes e mudas florestais. In: Aspectos silviculturais e ecológicos dos plantios florestais. UFSM. Santa Maria. p. 27-40.

Horvitz, C.C. and D.W. Schemske. 1986. Seed dispersal of a neotropical myrmecochore: variation in removal rates and dispersal distance. Biotropica, 18: 319-323.

Husband, B.C. and S.C.H. Barrett. 1996. A metapopulation perspective in plant population biology. J. Ecol., 84: 461-469.

Iverson, J.B. 1985. Lizards as seed dispersers? J. Herpetol., 19: 292-293.

Janssen, C. 1992. Flora und Vegetation von Halbtrockenrasen (Festuco-Brometea) im nördlichen Harzvorland Niedersachsens unter besonderer Berücksichtigung ihrer Isolierung in der Agrarlandschaft. Braunschw. Geobot. Arb., 2: 1-216.

Jenny, M. 1991. Diasporenausbreitung in ariden Standorten und ihre Klassifikation am Beispiel einer Annuellenflur im Wadi Araba (Jordanien). In: B. Schmid, J. Stöcklin, (eds.) Populationsbiologie der Pflanzen. Birkhäuser. Basel. p. 36-52.

Johnson, W.C. 1988. Estimating the dispersability of Acer, Fraxinus and Tilia in fragmented landscapes from patterns of seedling establishment. Landsc. Ecol., 1: 175-187.

Jordano, P. 2000. Fruits and frugivory. In: Fenner, 


\section{DISPERSÃO NATURAL DE SEMENTES EM PASTAGENS TROPICAIS}

M. (Ed.). Seeds, the ecology of regeneration in plant communities. CABI. Wallingford. p. 125165.

Kauter, D. 2002. "Sauergras" und "Wegbreit"? Die Entwicklung der Wiesen in Mitteleuropa zwischen 1500 und 1900. Berichte des Institutes für Landschafts- und Pflanzenökologie der Universität Hohenheim. Beiheft 14, 226 p.

Kellerer, C. und H. Albrecht. 1996. Ausbreitung von Pflanzen der landwirtschaftlichen Nutzflächen durch Rindergülle. Verhandlungen GfÖ, 26: 729-736.

Kleinschmidt, C. und G. Rosenthal. 1995. Samenbankpotential und Diasporenverdriftung in überschwemmten Feuchtwiesen. Kieler Notizen, 23: 40-44.

Knörzer, K.H. 1971. Urgeschichtliche Unkräuter im Rheinland. Ein Beitrag zur Entstehungsgeschichte der Segetalgesellschaften. Vegetatio, 23: 89-111.

Konold, W. und A. Hackel. 1990. Beitrag zur Geschichte der Streuwiesen und der Streuwiesenkultur im Alpenvorland. Zeitschr. $f$. Agrargesch. Agrarsoziol., 38: 176-191.

Krügel, M.M., M.I. Burger e M.A. Alves. 2006. Frugivoria por aves em Nectandra megapotamica (Lauraceae) em uma área de floresta estacional decidual no Rio Grande do Sul, Brasil. Iheringia, Sér. Zool., 96: 17-24.

Kwak, M.M., O. Velterop and J. Van Andel. 1998. Pollen and gene flow in fragmented habitats. Appl. Veg. Sci., 1: 37-54.

Lapenta, M.J. 2002. O mico-leão-dourado (Leontopithecus rosalia) como dispersor de sementes na reserva biológica união/IBAMA, Rio das Ostras, RJ. São Paulo, 2002. Dissertação de Mestrado (Mestrado em Ecologia). Universidade de SãoPaulo. São Paulo. 96 p.

Leal, I.R. and P.S. Oliveira. 1998. Interactions between fungus-growing ants (Attini), fruits and seeds in cerrado vegetation in southeast Brazil. Biotropica, 30: 170-178.

Levine, J.M. and D.J. Murrel. 2003. The communitylevel consequences of seed dispersal plants. Annu. Rev. Ecol. Evol. Syst., 34: 549-574.

Liebsch, D. 2007. Síndromes de dispersão de diásporos de um fragmento de floresta ombrófila mista em tijucas do sul, PR. Rev. Acad., 5: 167175.
Lima, R.L.S., L.S. Severino, G.B. Ferreira, M.I.L. Silva, R.C. Albuquerque e N.E.M. Beltrão. 2007. Crescimento da mamoneira em solo com alto teor de alumínio na presença e ausência de matéria orgânica. Rev. Bras. Oleagin. Fibr., 11: 15-21.

Lord, J.M. and J. Marshall. 2001. Correlations between growth form, habitat, and fruit colour in the New Zealand flora, with reference to frugivory by lizards. N.Z. J. Bot., 39: 567-576.

Luftensteiner, H.W. 1982. Untersuchungen zur Verbreitungsbiographie von Pflanzengemeinschaften an vier Standorten in Niederösterreich. Bibl. Bot., 135: 1-68.

Machado, L.A.Z., R.N. Denardin e A.V.A. Jacques. 1997. Percentagem e dureza do tegumento de sementes de três espécies forrageiras recuperadas em fezes ovina. Rev. Bras. Zootecn., 26: 42-45

Malo, J.E. and F. Suárez. 1995. Herbivorous mammals as seed dispersers in a Mediterranean dehesa. Oecologia, 104: 246-255.

Marimon, B.S. e J.M. Felfili. 2006. Chuva de sementes em uma floresta monodominante de Brosimum rubescens Taub. e em uma floresta mista adjacente no Vale do Araguaia, MT, Brasil. Acta Bot. Bras., 20: 423-432.

Mcallister, T.A. and K.J. Cheng. 1996. Microbial strategies in the ruminal digestion of cereal grains. Anim. Feed Sci. Technol., 62: 29-26.

McConkey, K.R. 2000. Primary seed shadow generated by gibbons in the rain forest of Barito Ulu, Central Borneo. Amer. J. Primatol., 52: 1329.

McDonald, D.W. and H. Smith. 1990. Dispersal, dispersion and conservation in the agricultural ecosystem. In: Bunce, R.G.H., D.C. Howard (Eds.). Species dispersal in agricultural habitats. Belhaven Press. London, New York. p. 18-34.

Medellin, R.A. and O. Gaona. 1999. Seed dispersal bats and birds in forests and disturbed habitats of Chiapas, Mexico. Biotropica, 31: 478-485.

Mercolli, C. and A.A. Yanosky. 1994. The diet of adult Tupinambis teguixin (Sauria: Teiidae) in the eastern chaco of Argentina. Herpetol. J., 4: 15-19.

Michael, P.J., K.J. Steadman, J.A. Plummer and P. Vercoe. 2006. Sheep rumen digestion and transmission of weedy Malva parviflora seeds. Austr. J. Exp. Agric., 46: 1251-1256.

Archivos de zootecnia vol. 58(R), p. 55. 
Mikich, S.B. and S.M. Silva. 2001. Composição florística e fenologia das espécies zoocóricas de remanescentes de floresta esta estacional semidecidual no centro-oeste do Paraná, Brasil. Acta Bot. Bras., 15: 89-113.

Mrotzek, R., M. Halder und W. Schmidt. 1999. Die Bedeutung von Wildschweinen für die Diasporenausbreitung von Phanerogamen. Verhandlungen GfÖ, 29: 437-443.

Müller-Schneider, P. 1977. Verbreitungsbiologie (Diasporologie) der Blütenpflanzen. Veröffentlichungen des Geobotanischen Instituts ETH - Stiftung Rübel, 61: 226.

Müller-Schneider, P. 1986. Verbreitungsbiologie der Blütenpflanzen Graubündens. Veröffentlichungen des Geobotanischen Instituts ETH - Stiftung Rübel, 85: 261.

Nascimento, V.L.A., L.L. Souza, J.A. Ferreira, W.M. Tomas, P.A.L. Borges, A. Desbiez e A Takahasi. 2004. Utilização de frutos de acuri (Attalea phalerata Mart. ex Spreng) por cutias (Dasyprocta azarae) no Pantanal da Nhecolândia. In: Simpósio Sobre Recursos Naturais e Sócio-Econômicos do Pantanal, 4., Anais... Embrapa Pantanal. Corumbá-MS.

Nogales, M., J.D. Delgado and F.M. Medina. 1998. Shrikes, lizards and Lycium intricatum (Solanaceae) fruits: a case of indirect seed dispersal on oceanic island (Alegranza, Canary Islands). J. Ecol., 86: 866-871.

Nogueira, A.C. 2002. Coleta, manejo, armazenamento e dormência de sementes. In: Restauração da Mata Atlântica em áreas de sua ocorrência natural. Embrapa Florestas. Colombo. p. 4552.

Ocumpaugh, W.R. and D.H.D. Swakon. 1993. Simulating grass seed passage through the digestive system of cattle. A laboratory technique. Crop Sci., 33: 1084-1090.

Olesen, J.M. and A. Valido. 2003. Lizards as pollinators and seed dispersers: an island phenomenon. Trends Ecol. Evol., 18: 177-181.

Oostermeijer, J.G.B., A. Berholz and P. Poschlod. 1996. Genetic aspects of fragmented plant populations. In: Settele, J., C. Margules, P. Poschlod, K. Henle (Eds.). Species survival in fragmented landscapes. Kluwer. Dordrecht. $p$. 92-101.

Opdam, P. 1990. Dispersal in fragmented populations: The key to survival. In: Bunce, R.G.H., D.C. Howard (Eds.). Species dispersal in agricultural habitats. Belhaven Press. London, New York. p. 3-17.

Özer, Z. 1979. Über die Beeinflussung der Keimfähigkeit der Samen mancher Grünlandpflanzen beim Durchgang durch den Verdauungstrakt des Schafes und nach Mistgärung. Weed Res., 19: 247-254.

Ozinga, W.A., J. Van Andel and A.M.P. Mcdonnell. 1997. Soil heterogeneity and mycorrhiza as determinants of plant species diversity. Acta Bot. Neer., 46: 237-254.

Pakeman, R. 2001. Plant migration rates and seed dispersal mechanisms. J. Biogeog., 28: 795800.

Pakeman, R.J., G. Digneffe and J.L. Small. 2002. Ecological correlates of endozoochory by herbivores. Funct. Ecol., 16: 296-304.

Passos, L. and S.O. Ferreira. 1996. Ant dispersal of Croton priscus (Euphorbiaceae) seeds in a tropical semideciduous forest in southeastern Brazil. Biotropica, 28: 697-700.

Peternelli, E.F.O., T.M.C. Della-Lucia e S.V. Martins. 2004. Espécies de formigas que interagem com as sementes de Mabea fistulifera Mart. (EUPHORBIACEAE). R. Árvore, 28: 733-738.

Piedade, M.T.F., P. Parolin e W.J. Junk. 2003. Estratégias de dispersão, produção de frutos e extrativismo da palmeira Astrocaryum jauari Mart. nos igapós do Rio Negro: implicações para a ictiofauna. Ecol. Apl., 2: 31-40.

Pizo, M.A. and I. Simão. 2001. Seed deposition patterns and the survival of seeds and seedlings of the palm Euterpe edulis. Acta Oecol., 22: 229-233.

Pizo, M.A., W.R. Silva, M. Galetti and R. Laps. 2002. Frugivory in coingas of the Atlantic Forest of southeast Brazil. Ararajuba, 10: 177-185.

Poschlod, P. and S. Bonn, S. 1998. Changing dispersal processes in the central European landscape since the last ice age - an explanation for the decrease of plant species richness in different habitats. Acta Bot. Neer., 47: 27-44.

Poschlod, P., S. Kiefer, U. Tränkle, S. Fischer and S. Bonn. 1998. Plant species richness in calcareous grasslands as affected by dispersability in space and time. J. Appl. Veg. Sci., 1: 75-90.

Pott, R. 1988. Entstehung von Vegetationstypen und Pflanzengesellschaften unter dem Einfluß des Menschen. Düsseldorfer Geobot. Koll., 5: 


\section{DISPERSÃO NATURAL DE SEMENTES EM PASTAGENS TROPICAIS}

27-54.

Pough, F.H., J.B. Heiser e W.N. Mcfarland. 1993. $A$ vida dos vertebrados. Atheneu. São-Paulo. $839 \mathrm{p}$.

Remešová, I. 2000. The viability of weed seeds in farmyard manure. Rostl. Výroba 46: 515-520.

Rezende, A.V., G.B.S. Almeida, H.H. Vilela, P.R.C. Landgraf, D.A. Nogueira e V.R.S. Correa. 2007. Germinação de sementes de gramíneas misturadas ao adubo químico para plantio. In: Congresso de Forragicultura e Pastagens, 2. Anais... Núcleo de Estudos de Forragicultura e Pastagens. UFLA. Lavras-MG.

Rieder, G. 1966. Der Einfluß des Schwemmistes auf die Unkrautverbreitung und die Anwendung der Tetrazolium-Methode bei Unkrautsamen. PhD thesis. University of Hohenheim. 119 p.

Rocha, V.J., N.R. Reis e M.L. Sekiama. 2004. Dieta e dispersão de sementes por Cerdocyon thous (Linnaeus) (Carnívora, Canidae), em um fragmento florestal no Paraná, Brasil. Rev. Bras. Zool., 21: 871-876.

Rodrigues, F.H.G. 2002. Biologia e conservação do lobo-guará na estação ecológica de águas emendadas, DF. Tese (Doutorado em Ecologia). Universidade Estadual de Campinas. Unicamp. 96p.

Rosito, M.J., E. Marchezan e M.G. Rocha. 2000. Avaliação da coleta e germinação de sementes de duas forrageiras de inverno recuperadas em fezes de bovinos sob pastejo. In: Reunião Anual da Sociedade Brasileira de Zootecnia, 37., Anais... Sociedade Brasileira de Zootecnia. Viçosa-MG.

Russi, L., P.S. Cocks and E.H. Roberts. 1992. The fate of legume seeds eaten by sheep from a Mediterranean grassland. J. Appl. Ecol., 29: 772-778.

Santo, M.M.E. 2007. Secondary seed dispersal of Ricinus communis Linnaeus (Euphorbiaceae) by ants in secondary growth vegetation in minas gerais. R. Árvore, 31: 1013-1018.

Santos, E.F. 1999. Ecologia alimentar e dispersão de sementes pelo lobo-guará (Chrysocyon brachyurus) em uma área rural no sudeste do Brasil (Carnivora: Canidae). Dissertação (Mestrado em Zoologia). Universidade Estadual Paulista Júlio de Mesquita Filho. UNESP. Rio Claro, SP. 68 p.

Saravy, F.P., P.J. Freitas, M.A. Lage, S.J. Leite,
L.F. Braga e M.P. Sousa. 2003. Síndrome de dispersão em estratos arbóreos em um fragmento de floresta ombrófila aberta e densa em alta floresta - MT. Revista do Programa de Ciências Agro-Ambientais, Alta Flor., 2: 1-12. Sato, T.M., F.C. Passos e A.C. Nogueira. 2008. Frugivoria de morcegos (Mammalia, Chiroptera) em Cecropia pachystachya (Urticaceae) e seus efeitos na germinação das sementes. Papéis Avulsos Zool., 48: 19-21.

Schneider, C., U. Sukopp und H. Sukopp. 1994. Biologisch-ökologische Grundlagen des Schutzes gefährdeter Segetalpflanzen. Schrift. f. Vegetationsk., 26: 1-356.

Schumacher, M.V., J.M. Hoppe e J.A. Farias. 2002. Manual de instruções para a coleta e beneficiamento, armazenamento e análise de sementes florestais. Projeto Bolsa de Sementes de Espécies Florestais - AFUBRA/UFSM. 1. 28 p.

Selter, B. 1995. Waldnutzung und ländliche Gesellschaft. Landwirtschaftlicher "Nährwald" und neue Holzökonomie im Sauerland des 18. und 19. Jahrhunderts. Forschungen zur Regional-geschichte, 13: 482.

Severino, L.S., G.B. Ferreira, C.R.A. Moraes, T.M.S. Godim, G.D. Cardoso, J.R. Viriato e N.E.M Beltrão. 2006. Produtividade e crescimento da mamoneira em resposta à adubação orgânica e mineral. Pesq. Agropec. Bras., 41: 879-882.

Silva, A., M.B. Figliolia e I.B. Aguiar. 1993. Secagem, extração e beneficiamento de sementes. In: Aguiar, I.B., F.C.M. Piña-Rodrigues, M.B. Figliolia, (Org.). Sementes florestais tropicais. Associação Brasileira de Tecnologia de Sementes. Brasília. p. 303-332.

Silva, P.D., I.R. Leal, R. Wirth and M. Tabarelli. 2007. Harvesting of Protium heptaphyllum (Aubl.) March. Seeds (Burseraceae) by the leaf-cutting ant $A t t a$ sexdens L. promotes seed aggregation and seedling mortality. Rev. Bras. Bot., 30: 553560.

Silva, T.O., J.C.C. Almeida, N.S. Rocha, Z.S. Costa, G.P. Lima, P.H. Grassi, T.C. Ferreira, R.P. Araújo e J.B.R. Abreu. 2007. Dispersão e germinação de leguminosas forrageiras tropicais através das fezes de bovinos. In: Congresso Internacional de Zootecnia, 9., Anais... Universidade Estadual de Londrina. Londrina-PR.

Silvertown, J.W. and J. Lovett-Doust, 1993. Introduction to Plant Population Biology. 


\section{DEMINICIS, VIEIRA, ARAÚJO, JARDIM, PADUA E CHAMBELANETO}

Blackwell. Oxford. 210 p.

Simão Neto, M., R.M. Jones and D. Ratcliff. 1987. Recovery of pasture seed fed to ruminants. I. Seed of tropical pasture species fed to catle, sheep and goats. Austr. J. Exp. Agric., 27: 239246.

Stender, S., P. Poschlod, E.Vauk-Hentzelt und T. Dernedde. 1997. Die Ausbreitung durch Galloway-Rinder. Verhandlungen GfÖ, 27: 173180.

Stern, M.D., A., Bach and S. Calsamiglia. 1997. Alternative techniques for measuring nutrient digestion in ruminants. J. Anim. Sci., 75: 22562276.

Strykstra, R.J., R.M. Bekker and G.L. Verweij. 1996. Establishment of Rhinanthus angustifolius in a successional hayfield after seed dispersal by mowing machinery. Acta Bot. Neer., 45: 557562.

Tackenberg, O. 1999. Bedeutung der Ausbreitung von Diasporen durch die Luft bei variablen meteorologischen Bedingungen. Schlussbericht des Teilprojektes III (FIFB-Verbundprojekt) an das BMBF. $137 \mathrm{p}$.

Tackenberg, O. 2001. Methoden zur Bewertung gradueller Unterschiede des Ausbreitungspotentials von Pflanzenarten. Dissert. Bot., 347: 1-138.

Teixeira, J.C. 1997. Nutrição de ruminantes. Edições FAEPE. Lavras. 239 p.

Thomson, E.F., S. Rihawi, P.S. Cocks, A.E. Osman and L. Russi. 1990. Recovery and germination rates of seeds of Mediterranean medics and clovers affected to sheep at a single meal or continuously. J. Agric. Sci., 114: 295-299.
Thompson, K., K.J. Gaston and S.R. Band. 1999. Range size, dispersal and niche breadth in the herbaceous flora of central England. J. Ecol., 87: 150-155.

Tiffney, B.H. 1984. Seed size, dispersal syndromes and the rise of the angiosperms: evidence and hypothesis. Ann. Miss. Bot. Gard., 71: 565-576.

Tokarnia, C.H., J. Döbereiner e P.V. Peixoto. 2000. Plantas tóxicas do Brasil. Ed. Helianthus. Rio de Janeiro. 310 p.

Tränkle, U. und P. Poschlod. 1995. Vergleichende Untersuchungen zur Sukzession von Steinbrüchen unter besonderer Berücksichtigung des Naturschutzes-Ergebnisse und Schlußfolgerungen. Veröffentlichungen PAÖ, 12: 167-178.

Van Der Pijl, L. 1982. Principles of dispersal in higher plants. $3^{a}$ ed. Springer-Verlag. New York.

Vitt, L.J., S.S. Sartorius, T.C.S. Avilla-Pires and M.C. Esposito. 2001. Life at the river's edge: ecology of Kentropyx altamazonica in Brasilian Amazonia. Can. J. Zool., 79: 1855-1865.

Waldhoff, D., B. Sant-Paul and U. Furch. 1996. Value of fruits and seeds from the floodplain forests of central Amazonia as food resource for fish. Ecotropica, 2: 143-156.

Willerding, U. 1986. Zur Geschichte der Ackerunkräuter Mitteleuropas. Göttinger Serien zur Vorund Frühgeschichte, 22: 1-369.

Whittaker, T.J. and S.H. Jones. 1994. The role of frugivorous bats and birds in the rebuilding of a tropical forest ecosystem, Krakatau, Indonesia. J. Biogeog., 21: 245-258.

Zobel, M., E. Van Der Maarel and C. Dupré. 1998. Species pool: the concept, its determination and significance for community research. J. Appl. Veg. Sci., 1: 55-66. 